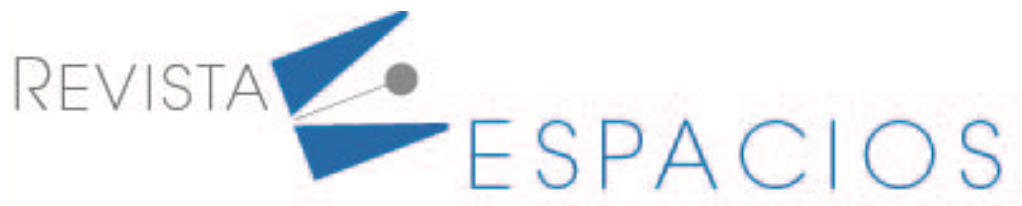

Vol. 42 (14) $2021 \cdot$ Art. 4

Recibido/Received: 09/05/2021 • Aprobado/Approved: 19/07/2021 • Publicado/Published: 30/07/2021

\title{
Analysis of redesigning the connecting rod and its influence on engine power of Honda 1300 cc year 1997
}

\section{Análisis del rediseño de la biela y su influencia en la potencia del motor Honda 1300 cc año 1997}

\author{
LASTRE, Arlys ${ }^{1}$ \\ RODRÍGUEZ, José ${ }^{2}$ \\ ORBEA, Luis ${ }^{3}$ \\ PINARGOTE, Franklin ${ }^{4}$
}

\begin{abstract}
The present work deals with the redesign of the connecting rod, as a link in the kinematic chain, defining itself as the main objective; to increase the power of the $\mathrm{MCl}$ by reason of geometric modifications assuring the fulfillment of the conditions of functionality and the restrictions of resistance by means of the use of systems CAD / CAE. Power measurements were made on a double roller dynamometer per axle before modifying the connecting rod and then with the proposed redesign variant, among which a contrast was made achieving an increase in power greater than $9 \%$, with a reduction of $39,08 \mathrm{gr}$ of material.
\end{abstract}

Key words: efficiency; redisign; connecting rod; systems cad/cae

\begin{abstract}
Resumen
El presente trabajo aborda el rediseño de la biela, como eslabón de la cadena cinemática, definiéndose como objetivo principal aumentar la potencia del $\mathrm{MCl}$ a razón de modificaciones geométricas de la misma asegurando el cumplimiento de las condiciones de funcionabilidad y las restricciones de resistencia mediante el empleo de sistemas CAD/CAE. Fueron realizadas mediciones de potencia en un dinamómetro de doble rodillo por eje antes de modificar las bielas y después con la variante de rediseño propuesta, entre las cuales se realizó un contraste logrando un aumento de la potencia mayor al 9\%, con una reducción del 39,08 gr de material.
\end{abstract}

Palabras clave: eficiencia, rediseño, biela, sistema cad/cae.

\section{Introduction}

The development of the automotive industry (Zhao, 2007) originates after the First World War, where the first productive processes were basically artisanal. The United States based on the organizational techniques in the production processes, proposed by Frederick Taylor (Rosenberg, 1963), introduces the first Ford Motors assembly line; for this reason the current of "Taylorism" discretized and implemented technological lines of work developed previously by qualified workers (Yin, Stecke, \& Li, 2018). On the other hand, the lines of processes were still carried out manually, although they focused on industrial development, which was established at the end of the 19th century mainly in production lines of Nordic countries such as United States, France, Germany

\footnotetext{
${ }^{1}$ Department of Electromechanical Engineering UTE University, Santo Domingo, 230102, Ecuador, Phone: +593 989951834 arlys.lastre@ute.edu.ec

2 Department of Automotive Engineering UTE University, Santo Domingo, 230102, Ecuador, Ecuador, Phone: +593969919588 jose.rodriguez@ute.edu.ec

${ }^{3}$ Department of Automotive Mechanic ITS JAPON, Santo Domingo, 230102, Ecuador, Ecuador, Phone +593989008572

${ }^{4}$ Department of Automotive Engineering UTE University, Santo Domingo, 230102, Ecuador, Ecuador
} 
and Italy, the same ones that years later became reference points for automotive development (Bouaziz, Zurob, \& Huang, 2013).

Up to mid-twentieth century research and development (R \& D) in the automotive industry focused on the normalization and physical reconversion of productive capital_being a differential factor, the dizzying expansion of Japanese industry (Thomke, 1998) only lower than the American, although at present it has been converted by the magnitude of production and innovation into the main producer of automobiles with more than 9 million per year (Sako \& Helper, 1998).

Likewise, the R \& D was implemented in the study of internal combustion engines (ICE) to improve efficiency since, the globalization of the industry was raised from the approach of taking advantage of all existing resources, therefore, the increase technology exponential has positioned itself in the premises of: optimize the power produced, generate a higher rate of revolutions per minute $(\mathrm{rpm})$ and decrease the loss of energy in the form of heat (Calabrese, 2001). The most significant R \& D in the automotive industry, have been achieved through the study the type of fuel (Hulwan \& Joshi, 2018; Ling \& Abas, 2018) the electronic optimization using neural processes of: (Klaumünzer et al. 2019), the reduction of kinematic pairs and the replacement of elements by others of better alloy and weight (Xu, Xu, \& Li., 2018).

However, the most applied procedures are: the reduction of kinematic pairs or the replacement of elements by others of better alloy and weight, although the existence of faults associated with these techniques usually deteriorate the functioning of the $\mathrm{MCl}$; among the most common faults are: premature wear of internal elements due to increased friction which generates a loss of energy in the form of heat, but ¿can be reduced mass of an internal element of the $\mathrm{MCl}$ without it suffering dimensional damage excessive in it's structure and still increase it's power?.

This question, whenever there are processes addressed in trying to increase the power of the $\mathrm{MCl}$ is raised and even more, when developers use it to incorporate their contributions to a state of the art (Garcia, Gordon, Aguilar, \& Aleaga, 2016), therefore, in the present study; employing finite element modeling, it is proposed to redesign the connecting rod of an $\mathrm{MCl}$; Honda of $1300 \mathrm{cc}$, year 1997, engine EB2, to determine its influence on the power and ensure that this does not result with gradual effects on its structure.

\section{Methodology}

To obtain the functioning indexes of the $\mathrm{MCl}$, a chassis transmission dynamometer, of Italian origin, VAMAG brand of double roller by train was used for the study of 2WD and 4WD tractions. The measurements made offered the values of the following parameters: Speed (mph), Wheel power (HP), Power of the MCl (HP), Normal power (HP) and Normal moment (lbf.ft) performed by the $\mathrm{MCl}$, all regarding, Revolutions per minute (rpm), these values were graphically represented and tabulated for the sake of their subsequent analysis and decision making during the redesign of the links in the kinematic chain, connecting rod, crank-piston. In this way the dimensional modifications of the; connecting rod, objective of the present work, will be established by the compliance of the restrictions of functionality and mechanical strength of said link in the aforementioned chain of kinematics.

The variant of redesign of the connecting rod implies a reduction of mass due to dimensional modifications, which presupposes an improvement of the power of the engine and in this way a better performance of the car.

With the employ of CAD / CAE technologies (Garcia, Gordon, Aguilar, \& Aleaga, 2016) the modeling of the connecting rod will be developed based on its dimensions and original material. Saying model will allow the generation of different variants of dimensional redesign, which will be subjected to simulation from the working conditions and we will obtain the maximum allowed dimensional reductions that do not compromise the stiffness and resistance restrictions of the connecting rod (Garcia, Gordon, Aguilar, \& Aleaga, 2016). 


\subsection{Standard connecting Rod Modeling}

The longitudinal measures of the standard connecting rod are: on the $X$ axis; $5.6 \mathrm{~cm}$; the $Y$ axis; $16.92 \mathrm{~cm}$; and, the $Z$ axis; $2.2 \mathrm{~cm}$. The type of material is, AISI 4340; It has a weight of 408.6 grams (gr) and, its volume is; 52.05 $\mathrm{cm} 3$. The subsequent modeling is performed, the number of nodes used is 581105 . These data are considered as point of origin for the subsequent comparison with the final redesign variant. Figure 1, shows the geometric modeling of the weighted standard connecting rod. Modeled in SolidWorks and transferred to ANSYS for the dynamic analysis of the variables.

Figure 1

Geometric design of the connecting rod, with standard measurements

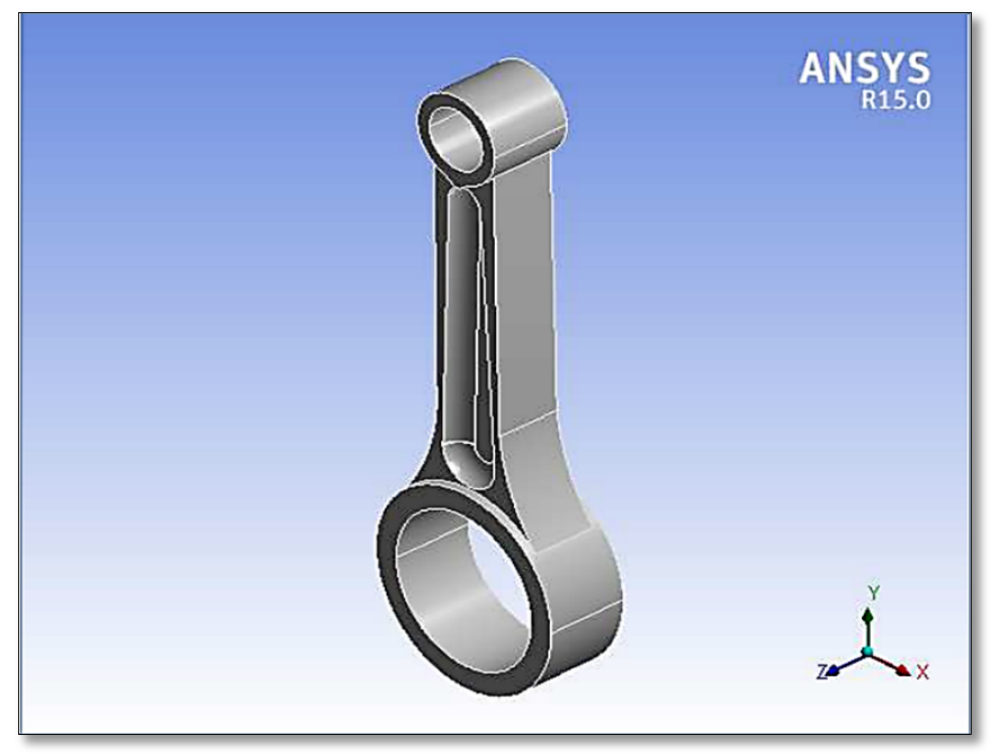

\subsection{Design of the algorithm for the analysis of the connecting rod in a CAE system}

For the generation of the possible variants of solution and its subsequent performance contrast with the parameters obtained in the measurements of origin, an algorithm (Ruiz, Aleaga, Cordovés, \& Asgher, 2019) is proposed that defines in a hierarchical way the actions for the analysis of the connecting rod in a CAE system which will allow the selection and description of the variant definitive redesign.

Figure 2, the proposed algorithm is illustrated: The process contains as input data the modeling of the connecting rod in CAD, for the subsequent dimensional modifications, and the corresponding generation of the mesh discretized in a CAE system, to establish and verify the conditions of: resistance and rigidity to which the connecting rod will be subjected, such as: forces, equivalent tension, equivalent elastic tension and total deformation. Then, it is posed the condition of resistance in the process; if the connecting rod resists other limits are established for the new modification, if it does not resist the process; it is considered to the last dimensional modeling that resisted as; the final variant and the selection process is finished. 
Figure 2

Design of the algorithm to obtain the redesign variant of the connecting rod.

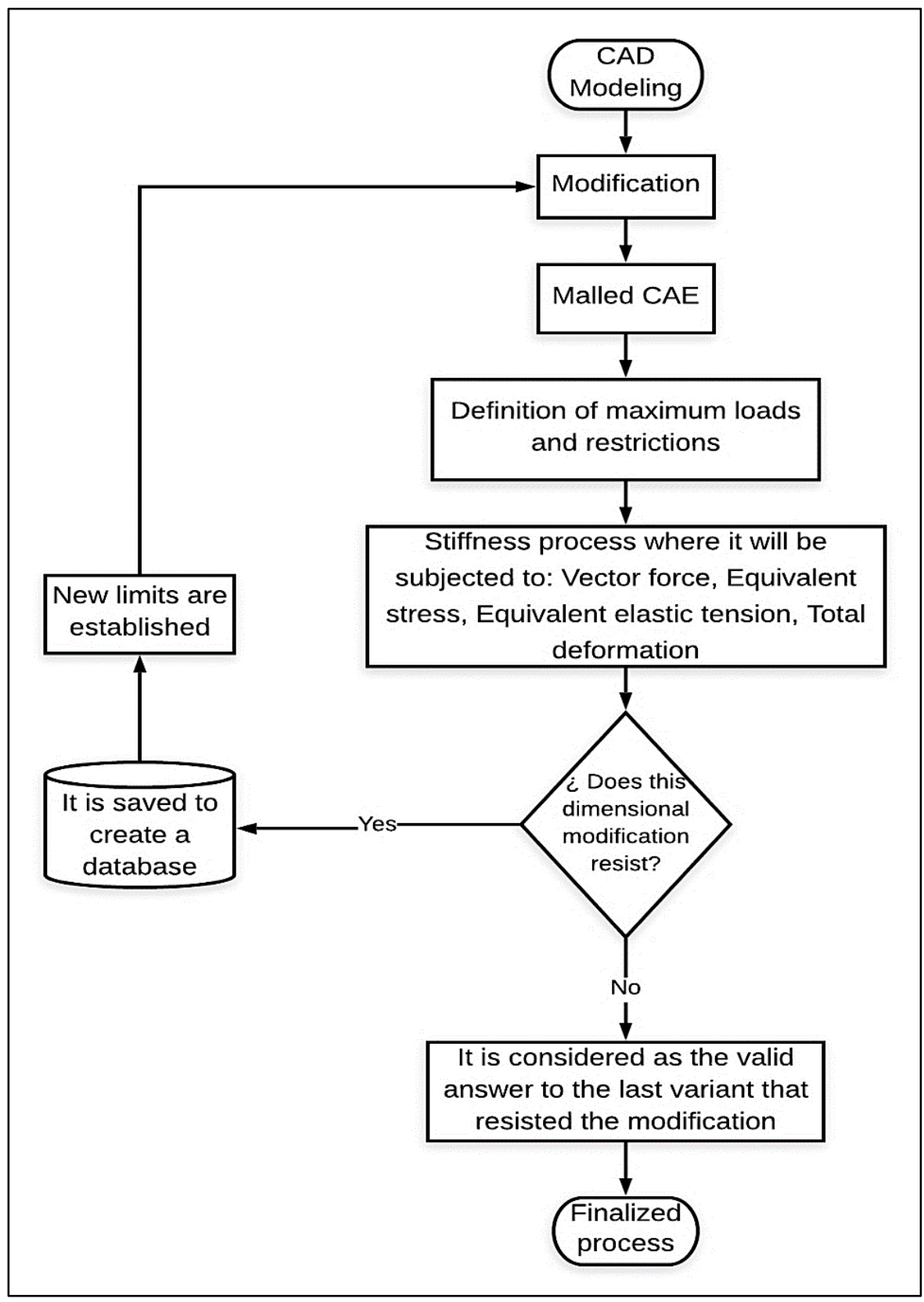

\subsection{Description of the final variant (redesigned connecting rod)}

With the implementation of the algorithm, the definitive redesign solution was obtained. The longitudinal dimensions of the redesigned connecting rod are: on the $X$ axis; $5.4 \mathrm{~cm}$; the $Y$ axis; $16.92 \mathrm{~cm}$; and, the $Z$ axis; 2 $\mathrm{cm}$. The type of material is, AISI 4340; It has a weight of $369.52 \mathrm{gr}$ and, its volume is; $47,072 \mathrm{~cm} 3$. The number of employed nodes, 635296. 
Figure 3 , is divided into 6 variants $(a, b, c, d, e, f)$ that describe the variant of final redesign of the connecting rod, values higher than this, caused deformations in the radius of agreement between body and foot of connecting rod (smaller diameter), as well as in the radius of agreement between body and connecting rod head (larger diameter).

For this reason, the foundation of the final variant is detailed as follows: The variant (a): mesh that has the redesign variant; variant (b): geometric modeling; variant (c): analyzes the force vector in relation to time in this case to a second (1s), with a force exerted on the $Y$ axis, in a descending manner, since in the order of links of the kinematic chain, the foot of connecting rod coupled to the bolt and piston absorb the combustion time that is generated in the $\mathrm{MCl}$ and moves it throughout the body to generate moment in the crankshaft, it originates a cyclical process of the times in the $\mathrm{MCl}$ and its operating system, the force that is generated is $-31671 \mathrm{~N}$; variant (d): equivalent stress that originates in the whole connecting rod from from the foot to the head, in relation to the time in this case to one second (1s), the stress generated in the foot is $373680000 \mathrm{~Pa}$, the distance that makes the pressure throughout the body itself, that the material absorbs until reaching the head where, the stress is 42173Pa; variant (e): elastic equivalent stress, defined as; the internal force to which the connecting rod of both tension and compression is subjected, in which the same route as (d) is carried out, the elastic tension generated in the foot is $0.0018325 \mathrm{~m} / \mathrm{m}$, while in the head of is $0.00000067614 \mathrm{~m} / \mathrm{m}$; variant (f): total deformation experienced by the connecting rod, the form of analysis is symmetric to (d) and (e): total deformation generated in the foot is $0.00027978 \mathrm{~m}$, while in the head is $0.000038906 \mathrm{~m}$.

Figure 3

Variant of final redesign of the connecting rod.

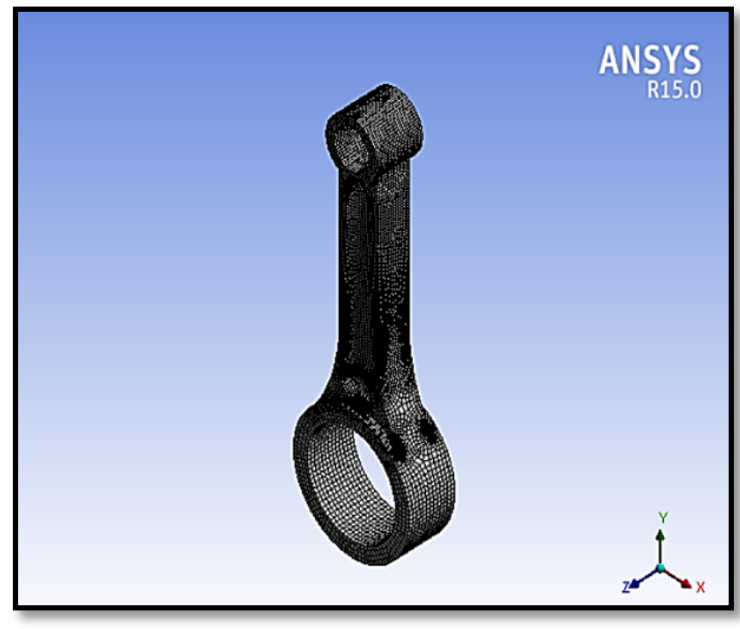

(a)

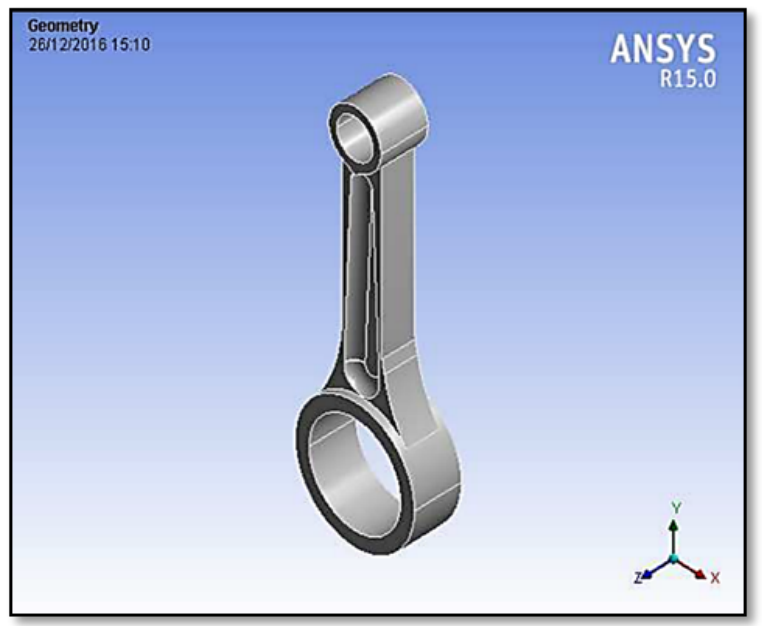

(b) 


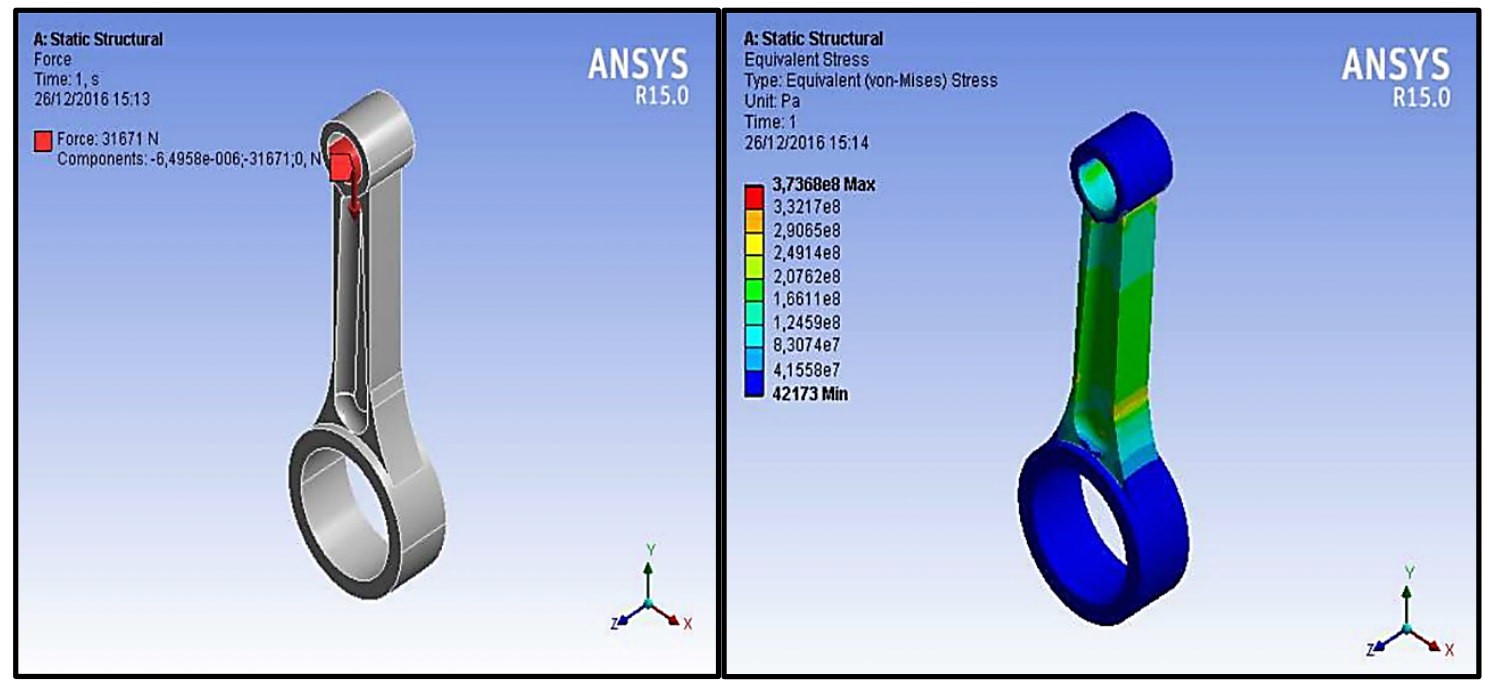

(c)

(d)

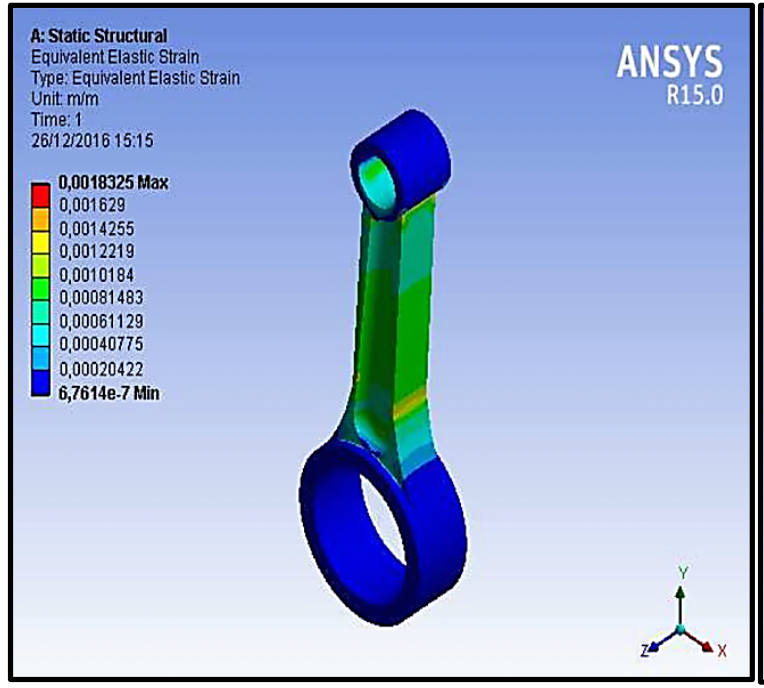

(e)

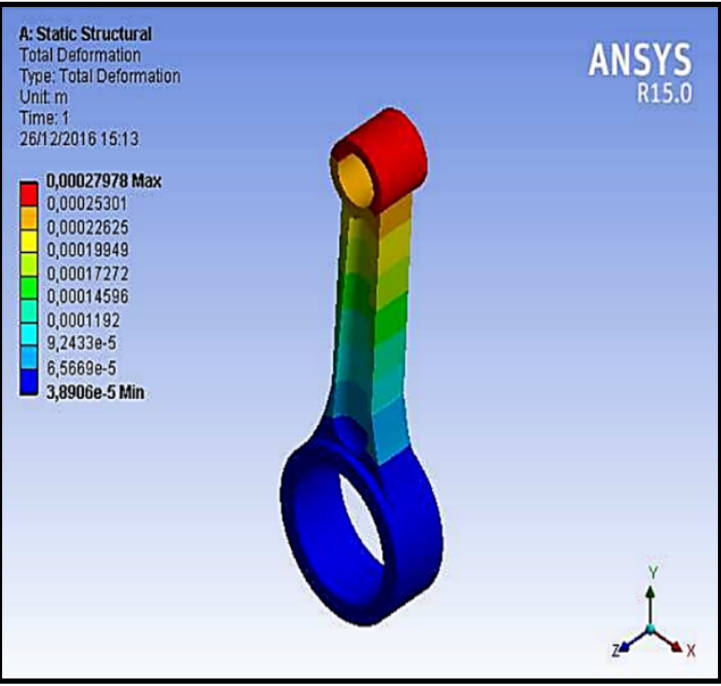

(f)

\section{Results}

Table 1, details the comparison of the results of the standard connecting rod with the redesign variant. In which, it has generated a differential function based on variables: The volume decreased 4,978 $\mathrm{cm} 3$ and the weight $39.08 \mathrm{~g}$, expressed as a percentage; it is equivalent to $9.564 \%$ less volume and weight than the standard connecting rod. 
Table 1

Results of the parameters of the standard connecting rod and the final version of redesign.

\begin{tabular}{|c|c|c|c|c|}
\hline \multirow[t]{2}{*}{ Variables } & \multirow{2}{*}{\multicolumn{2}{|c|}{$\begin{array}{l}\text { Measurement indices in the } \\
\text { study }\end{array}$}} & \multicolumn{2}{|c|}{$\begin{array}{l}\text { Comparison between original design and redesign of the } \\
\text { connecting rod }\end{array}$} \\
\hline & & & Standard modeling & $\begin{array}{l}\text { Definitive redesign } \\
\text { variant }\end{array}$ \\
\hline \multirow{3}{*}{ Lengths } & $x$ & & $5,6 \mathrm{~cm}$ & $5,4 \mathrm{~cm}$ \\
\hline & Y & & $19,62 \mathrm{~cm}$ & $19,62 \mathrm{~cm}$ \\
\hline & Z & & $2,2 \mathrm{~cm}$ & $2 \mathrm{~cm}$ \\
\hline \multirow{4}{*}{ Properties } & Volume & & $52,05 \mathrm{~cm}^{3}$ & $47,072 \mathrm{~cm}^{3}$ \\
\hline & Weight & & $408,6 \mathrm{gr}$ & $369,52 \mathrm{gr}$ \\
\hline & Nodes & & 581105 & 635296 \\
\hline & Force applied in & & $31671 \mathrm{~N}$ & $31671 \mathrm{~N}$ \\
\hline \multirow{6}{*}{$\begin{array}{c}\text { Measurement and } \\
\text { comparison } \\
\text { parameters }\end{array}$} & & Foot & $310240000 \mathrm{~Pa}$ & $373680000 \mathrm{~Pa}$ \\
\hline & Equivalent Stress & Head & $53605 \mathrm{~Pa}$ & $42173 \mathrm{~Pa}$ \\
\hline & Equivalent Elastic & Foot & $0,0015216 \mathrm{~m} / \mathrm{m}$ & $0,0018325 \mathrm{~m} / \mathrm{m}$ \\
\hline & Tensión & Head & $0,00000031218 \mathrm{~m} / \mathrm{m}$ & $0,00000067614 \mathrm{~m} / \mathrm{m}$ \\
\hline & & Food & $0,000089125 \mathrm{~m}$ & $0,00027978 \mathrm{~m}$ \\
\hline & Total deformation & Head & $0,0000048264 \mathrm{~m}$ & $0,000038906 \mathrm{~m}$ \\
\hline
\end{tabular}

Subsequently, the reduction of mass to the other connecting rods is made and the operating indexes of the $\mathrm{MCl}$ are contrasted using the dynamometer. Figure 4, is divided into 5 parameters $(a, b, c, d, e)$ that will allow to analyze the behavior of the $\mathrm{MCl}$ according to the requirements, with respect to; $\mathrm{n}$ (revolutions per minute). The starting point is $2000 \mathrm{rpm}$ and the Speed (mph), Wheel power (HP), MCl power (HP), Normal power (HP) and Normal moment (lbf.ft) performed by the $\mathrm{MCl}$ are analyzed.

The Parameter (a): reference to the speed developed by the vehicle; the parameter (b): reference to wheel power; the parameter $(c)$ : reference the power developed by the motor; the parameter $(d)$ : reference the normal power developed by the vehicle and the parameter (e): reference the normal moment of the engine. The most significant results obtained are the following:

- The increase of $500 \mathrm{rpm}$ with the variant of redesign of the connecting rod, what percentage represents an increase of $9.0901 \%$.

- The behavior of the $\mathrm{MCl}$ with the redesigned connecting rod, when studying the speed developed by the vehicle has a point of origin with respect to the higher mph than it has, the $\mathrm{MCl}$ with the standard connecting rod and maintains the trend.

- The behavior of the $\mathrm{MCl}$ with the redesigned connecting rod, when studying the power of the wheel, the point of origin with respect to the HP is greater than that of the $\mathrm{MCl}$ with the standard connecting rod, in addition, when the $\mathrm{MCl}$ with the redesigned connecting rod is in the range of ; 2900 to $4300 \mathrm{rpm}$ experiences its maximum power and, when the threshold of $5000 \mathrm{rpm}$ passes; it marks a tendency of balance, unlike the behavior of the $\mathrm{MCl}$ with the standard connecting rod, that the behavior ends in a descending manner contrasted to the axis of the rpm.

- The behavior of the $\mathrm{MCl}$ with the redesigned connecting rod, when studying the power of the 
engine, the point of origin with respect to the $\mathrm{HP}$ is greater than that of the $\mathrm{MCl}$ with the standard connecting rod, in addition when the $\mathrm{MCl}$ with the rod redesigned in the range of; 3900 to 5000 rpm the engine experiences its maximum power and, when the threshold of $5000 \mathrm{rpm}$ passes, the trend is of linear equilibrium without alteration contrasted to the axis of the rpm.

- The behavior of the $\mathrm{MCl}$ with the redesigned connecting rod, when studying the normal power of the vehicle, the point of origin with respect to the HP is greater than that of the $\mathrm{MCl}$ with the standard connecting rod, additionally when the $\mathrm{MCl}$ with the redesigned connecting rod is in the interval of; 48000 at $5500 \mathrm{rpm}$ the vehicle experiences its maximum normal power even more, when the threshold of $5000 \mathrm{rpm}$ passes; its tendency marks a very ascending curve, unlike the behavior of the $\mathrm{MCl}$ with the standard connecting rod, that the behavior ends with a tendency of equilibrium contrasted to the axis of the rpm

- The behavior of the $\mathrm{MCl}$ with the redesigned connecting rod, when studying the normal moment of the engine, its point of origin with respect to the lbf. $\mathrm{ft}$ is greater than that of the $\mathrm{MCl}$ with the standard connecting rod, in addition when the $\mathrm{MCl}$ with the redesigned connecting rod is in the interval of; 4400 to $5000 \mathrm{rpm}$ this one experiences its minimum normal moment and, when it passes the threshold of $5000 \mathrm{rpm}$; it marks a tendency of equilibrium, unlike the behavior of the $\mathrm{MCl}$ with the standard connecting rod that, the behavior ends in a descending way contrasted to the axis of the rpm.

- The result of the study of the powers: of the wheel, motor and normal gradually increase and their highest power peaks are reached in the range of; 2900 to $5000 \mathrm{rpm}$, unlike the normal power that your highest range is of; 4800 to $5500 \mathrm{rpm}$.

- The normal moment increases due to the lightening of the mass of the link in the kinematic chain; connecting rod, crank-piston and therefore, the mass detached from the element is derived in increased angular velocity.

Figure 4

Behavior curves of the $\mathrm{MCl}$, with the standard connecting rod and with the variant of redesigned contrasted by the use of the dynamometer

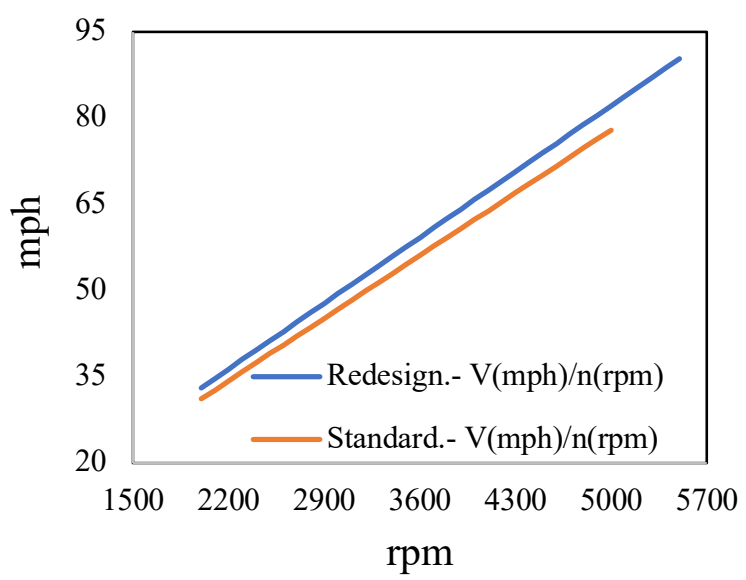

(a)

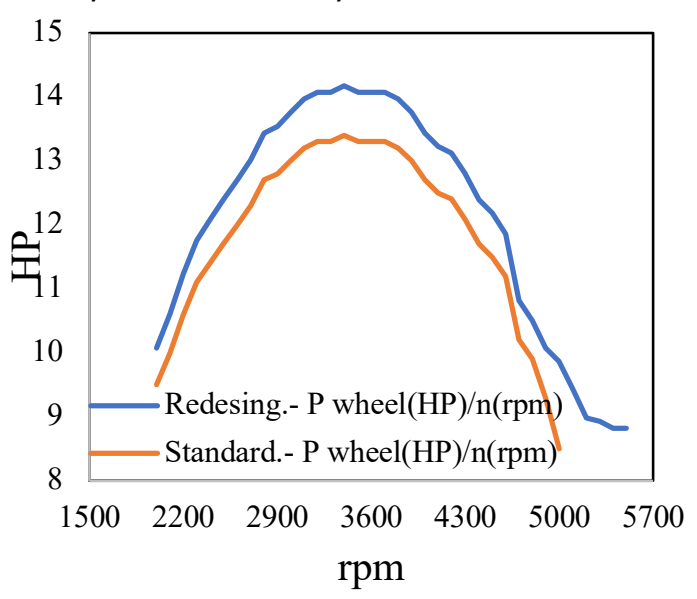

(b) 


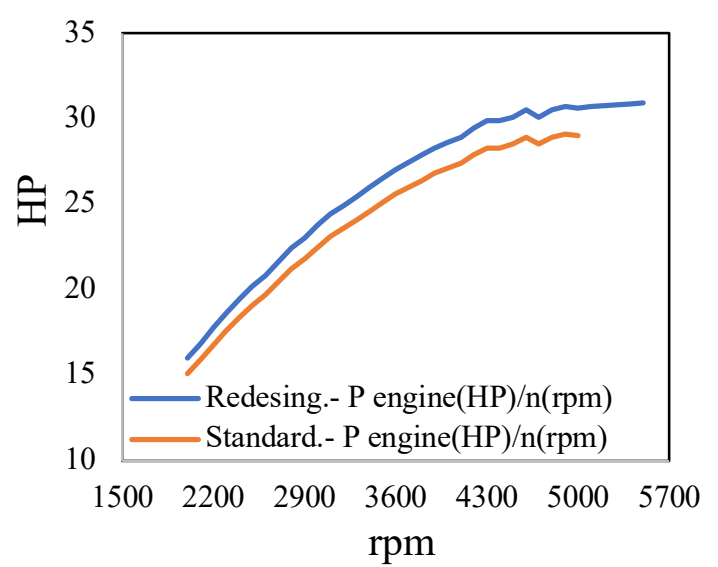

(c)

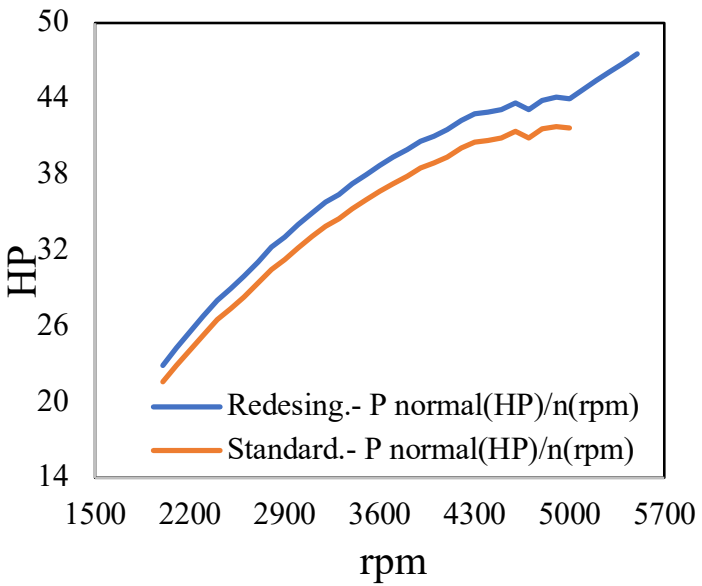

(d)

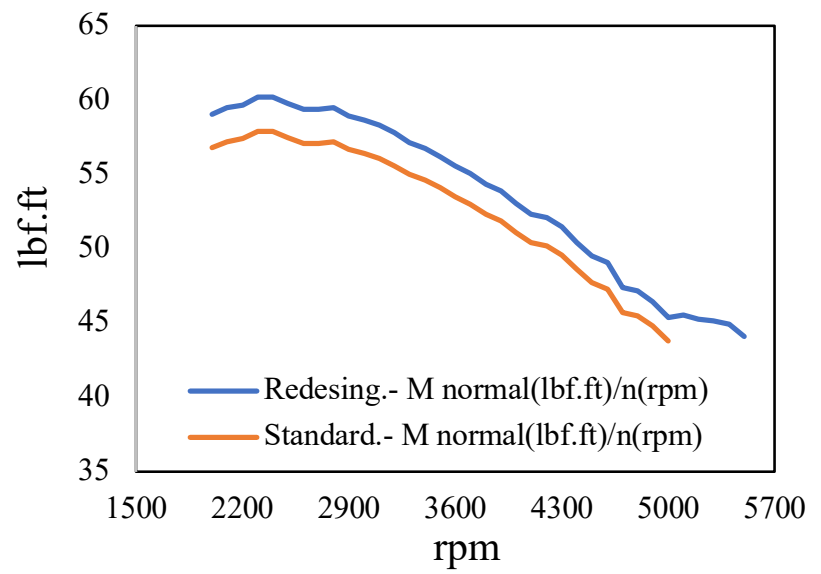

(e)

\section{Conclusions}

An exhaustive analysis of the state of the art was carried out, which allowed to establish the scientific-technical principles that determine the design of the connecting rod.

An algorithm was developed for the generation and analysis of design variants in a CAD/CAE environment.

The integration of the principles of mechanical strength in a CAD/CAE environment allowed the analysis of solution variants and the final selection of the modifications made to the original connecting rod.

It was possible to increase the power of the $\mathrm{MCl}$ by reducing a $9.564 \%$ mass in each of the connecting rods without affecting the condition of their resistance and rigidity and the kinematic torque's functionality.

\subsection{Recommendations}

Include in the analysis new variables in decision making such as: material, tribological conditions, among others.

Make extensived this analysis to other elements of the kinematic pair.

\section{Bibliographic references}

Bouaziz, O., Zurob, H., \& Huang, M. (2013). Driving force and logic of development of advanced high strength steels for automotive applications. Steel research international, 84(10), 937-947. 
Calabrese, G. (2001). R\&D globalisation in the car industry. International Journal of Automotive Technology and Management, 1(1), 145-159.

Garcia, A. C., Gordon, G. M., Aguilar, J. A., \& Aleaga, A. M. (2016). Estimation of the thermal loads on buildings with CAD systems support. International Symposium on Mechanical Engineering and Material Science.

Hulwan, D. B., \& Joshi, S. V. (2018). Multizone Model Study for DI Diesel Engine Running on Diesel-EthanolBiodiesel Blends of High Ethanol Fraction. International Journal of Automotive and Mechanical Engineering, 15(3), 5451-5467.

Klaumünzer, D., Hernandez, J. V., Yi, S., Letzig, D., Kim, S.-h., Kim, J. J., . . . Ahn, K. (2019). Klaumünzer, David, et al. "Magnesium Process and Alloy Development for Applications in the Automotive Industry. Magnesium Technology 2019, 15-20.

Ling, C. H., \& Abas, M. A. (2018). One-Dimensional Simulation Using Port Water Injection for a Spark Ignition Engine. International Journal of Automotive and Mechanical Engineering, 15(4), 5803-5814.

Rosenberg, N. (1963). Technological change in the machine tool industry, 1840-1910. The Journal of Economic History, 23(4), 414-443.

Ruiz, J. A., Aleaga, A. M., Cordovés, A., \& Asgher, U. (2019). Using Adaptive Integration of Variables Algorithm for Analysis and Optimization of 2D Irregular Nesting Problem. International Conference on Applied Human Factors and Ergonomics.

Sako, M., \& Helper, S. (1998). Determinants of trust in supplier relations: Evidence from the automotive industry in Japan and the United States. Journal of Economic Behavior \& Organization, 34(3), 387-417.

Thomke, S. H. (1998). Simulation, learning and R\&D performance: Evidence from automotive development. Research Policy, 27(1), 55-74.

Xu, L. D., Xu, E. L., \& Li., L. (2018). Industry 4.0: state of the art and future trends. International Journal of Production Research, 56(8), 2941-2962.

Yin, Y., Stecke, K. E., \& Li, D. (2018). The evolution of production systems from Industry 2.0 through Industry 4.0. International Journal of Production Research, 56(1.2), 848-861.

Zhao, H. (2007). HCCl and CAl engines for the automotive industry. Elsevier.

Esta obra está bajo una Licencia Creative Commons Attribución-NoCommercial 4.0 International

\section{(cc) EY-NC}

